\title{
REVIEW
}

\section{Genetic profiling and epidermal growth factor receptor-directed therapy in nonsmall cell lung cancer}

\author{
J. Cadranel*, G. Zalcman" and L. Sequist ${ }^{\Uparrow}$
}

ABSTRACT: The principle of preferentially selecting patients most likely to benefit from therapy according to their genetic profile has led to substantial clinical benefit in some tumour types, and has potential to considerably refine treatment in advanced nonsmall cell lung cancer (NSCLC). Effective, reliable use of molecular biomarkers to inform clinical practice requires the standardisation of testing methods and careful assessment of biomarkers' predictive and prognostic value.

Although a number of studies have shown that patients with activating mutations in exons 18-21 of the epidermal growth factor receptor (EGFR) gene respond particularly well to gefitinib and erlotinib, a prospective, randomised study was needed to differentiate between the prognostic and predictive value of EGFR mutations. From one such study, it appeared that mutational testing should become standard at diagnosis, at least for adenocarcinoma patients with a never or low smoking history, as clinical predictors are insufficient to optimise treatment.

However, outstanding questions remain: what are the treatment options for patients with tumours resistant to erlotinib/gefitinib? What conclusions about treatment can we draw from EGFR copy number or KRAS mutation status? What role should anti-EGFR antibodies play in NSCLC treatment, and in which patients?

This review considers current evidence linking biomarker profile to efficacy of EGFR-targeted therapy in NSCLC, and clinical implications of recent findings.

KEYWORDS: Biomarker, epidermal growth factor receptor, epidermal growth factor receptor inhibitors, genetic profiling, mutational testing, nonsmall cell lung cancer

\section{ESTABLISHING THE PRINCIPLE OF MUTATION TESTING: LESSONS FROM OTHER TUMOUR TYPES}

Therapies tailored to specific genetic lesions and diagnostic tests that assay for their respective molecular targets are now an established part of clinical practice across various tumour types, including chronic myeloid leukaemia [1], gastrointestinal stromal tumours and epithelial tumours, such as breast and colon cancer [2].

Clinically relevant improvements in survival have been attained by administering targeted therapy to the appropriate patient population: for example, the addition of trastuzumab to standard first-line chemotherapy in patients with human epidermal growth factor receptor-positive (HER2+) metastatic breast cancer [3]. A HER2 amplification diagnostic test is now required in breast cancer before patients are treated with trastuzumab [2]. Clinical practice in colon cancer also reflects the need for mutational testing to identify patients most likely to benefit from cetuximab: patients whose tumours lack a KRAS mutation (also called wild-type) show significantly increased overall survival (OS) (median 9.5 versus 4.8 months) with cetuximab, whereas those with KRAS mutations do not benefit from therapy [4].

These successful examples validate the concept of understanding the genetic profile of patients most likely to benefit from a targeted agent and preferentially selecting those patients for therapy. However, the use of molecular biomarkers to optimise clinical outcomes requires careful
AFFILIATIONS

*Hôpital Tenon, Assistance PubliqueHôpitaux de Paris and Faculté de Médecine Pierre et Marie Curie, Université Paris VI, Paris, and

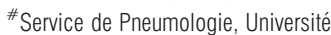
de Caen-Basse-Normandie, CHU de Caen, Caen, France.

- Massachusetts General Hospital Cancer Center, Harvard Medical School, Boston, MA, USA.

\section{CORRESPONDENCE}

J. Cadranel

Service de Pneumologie

Hôpital Tenon

4 rue de la Chine

75970

Paris

France

E-mail: jacques.cadranel@

tnn.aphp.fr

Received:

Nov 112009

Accepted after revision:

May 062010 
assessment of their role in terms of both prognosis and treatment decision-making. Specifically, it is becoming increasingly important to accurately distinguish biomarkers as "prognostic" or "predictive", or define them as both. Prognostic biomarkers can be thought of as a measure of the natural history of a disease that is independent of therapeutic intervention (or lack of it) [5]. A population-based register or a placebo/control group from a randomised clinical study is appropriate for evaluating the prognostic value of a biomarker [5]. In contrast, a predictive biomarker differentiates a group with a particular response or lack of response to a therapeutic intervention. In order to establish which patients will benefit most from a treatment, and by how much, the predictive value of a biomarker must be separated from its prognostic value. To do this, experimental and control arms can be stratified by biomarker status and an interaction test performed. It is recommended, in most cases, that biomarkers should be evaluated prospectively rather than retrospectively.

This review considers the current evidence linking biomarker profile to efficacy of epidermal growth factor receptor (EGFR)targeted therapy in advanced nonsmall cell lung cancer (NSCLC) and the clinical implications of recent findings.

\section{EGFR TYROSINE KINASE INHIBITOR: THE FIRST TARGETED THERAPY IN NSCLC}

In NSCLC, activation of the EGFR/HER1 pathway results in a signalling cascade that promotes tumour growth and progression [6]. EGFR is expressed in a large proportion of NSCLC tumours [7], and its associated signalling pathways are frequently dysregulated. These observations provided the rationale for developing small-molecule tyrosine kinase inhibitors (TKIs) targeting EGFR, erlotinib and gefitinib, and EGFR-targeted antibodies, such as cetuximab.

Gefitinib is currently the most widely used EGFR TKI worldwide. It has single-agent activity in patients previously treated with chemotherapy $[8,9]$, but did not prolong survival compared with placebo in the Iressa Survival Evaluation in Lung Cancer (ISEL) randomised, phase III trial in the secondand third-line setting [10]. When compared with single-agent chemotherapy, it has been shown to be non-inferior to docetaxel, with improved quality of life in a large phase III study of previously treated patients [11]; in a smaller, randomised phase II study of chemotherapy-naïve elderly patients, gefitinib improved quality of life, without progression-free survival (PFS) or OS decrement, compared with vinorelbine [12]. First-line addition of gefitinib to cisplatin and gemcitabine (Iressa NSCLC Trial Assessing Combination Treatment (INTACT)-1) [13] or carboplatin and paclitaxel (INTACT-2) [14] showed no significant difference in response rate (RR) or survival compared with chemotherapy alone.

Erlotinib is the most widely used EGFR TKI in the USA and European Union, and has shown single-agent antitumour activity and symptom improvement in previously treated NSCLC patients [15]. In contrast to gefitinib, second- and thirdline erlotinib significantly improved OS compared with placebo in the BR.21 Phase III trial (6.7 versus 4.7 months; hazard ratio $(\mathrm{HR})$ 0.70; $\mathrm{p}<0.001)$ [16]. Like the combination trials with gefitinib, phase III trials combining erlotinib with first-line chemotherapy (Tarceva Lung Cancer Investigation and Tarceva Responses in Conjunction with Taxol and Carboplatin (TRIBUTE)) showed no significant difference in survival between erlotinib and control arms [17, 18]. Finally, the phase III Sequential Tarceva in Unresectable NSCLC (SATURN) trial assessed the efficacy of maintenance erlotinib compared with placebo in patients with advanced NSCLC who did not show disease progression after first-line, platinumbased doublet chemotherapy. This trial demonstrated a significant improvement in PFS for the 437 patients receiving erlotinib, compared with the 447 patients receiving placebo (PFS at 24 weeks 31 versus 17\%; HR 0.71, 95\% CI 0.62-0.82; logrank $\mathrm{p}<0.0001)$ [19].

To summarise, both gefitinib and erlotinib are considered to be active single-agent therapies in NSCLC patients treated previously with chemotherapy. Reasons for the discrepancy between the BR.21 and ISEL trial outcomes, when both drugs are chemically and preclinically similar, may be due to dosing: erlotinib is dosed at $150 \mathrm{mg} \cdot \mathrm{day}^{-1}$, its maximum tolerated dose (MTD), whereas gefitinib is dosed at $250 \mathrm{mg} \cdot \mathrm{day}^{-1}$, about onethird to one-half of its MTD [20]. Other contributing factors could be differences in the populations studied in the two trials, including divergent representation of patients most likely to respond, and differences in the definition of secondline patients, either as those with progressive or those with stable disease after first-line treatment.

\section{EGFR MUTATIONS IN NSCLC: IMPLICATIONS FOR FIRST-LINE TREATMENT WITH EGFR TKIS}

A subset of patients responds particularly well to EGFR TKIs. Even in early studies, it was apparent that gefitinib and erlotinib were associated with greater responses in patients with adenocarcinoma, never-smokers, patients from East Asia and females [21]. Somatic activating mutations of the EGFR gene have now been identified; these mutations confer an increased susceptibility to EGFR TKI-mediated cell death and probably underlie the increased responses observed in these clinically defined groups [22-24]. Two EGFR mutations, the exon 19 deletion and the exon 21 L858R substitution, account for $\sim 90 \%$ of all known EGFR kinase domain mutations [25].

A substantial body of evidence verifies the importance of EGFR mutational status in determining which patients are most likely to respond to treatment with erlotinib/gefitinib. Both retrospective studies of second- and third-line EGFR TKIs in unselected populations, as well as prospective studies of first-line EGFR TKI treatment in enriched populations, have been published (table 1). Over a number of studies, the weighted average RR to EGFR TKI treatment in mutationpositive cases was $78 \%$, with most series reporting a RR of more than $60 \%$. In mutation-negative cases, in contrast, the average $\mathrm{RR}$ was $10 \%$ [38]. This is evidence that EGFR mutations are associated with response to EGFR TKI therapy.

The studies mentioned above include an evaluation of the impact of EGFR mutations on survival after gefitinib approval, compared with historical controls (EGFR mutants diagnosed and treated before gefitinib approval). A significant association between EGFR mutations and prolonged survival was shown with gefitinib [39]. Taken together, these studies suggest that EGFR mutational status may be a predictive biomarker. Furthermore, patients with the exon 19 deletion mutation 


\begin{tabular}{|c|c|c|c|c|c|c|}
\hline First author [ref.] & $\begin{array}{c}\text { Patients screened } \\
\mathbf{n}\end{array}$ & $\begin{array}{c}\text { EGFR mutations } \\
\mathbf{n}\end{array}$ & $\begin{array}{c}\text { Patients treated } \\
\mathbf{n}\end{array}$ & $\begin{array}{l}\text { Treatment } \\
\text { line }\end{array}$ & Drug & $\begin{array}{c}\mathrm{RR} \%(95 \% \mathrm{Cl}) \text { in EGFR } \\
\text { mutation-positive patients }\end{array}$ \\
\hline Asahina [26] & 82 & 20 & 16 & First-line & Gefitinib & 75 (48-93) \\
\hline YoshiDA [27] & 66 & 27 & 21 & Mixed & Gefitinib & $90.5(69.6-98.8)$ \\
\hline Мок [29] & 683 & 261 & NR & First-line & Gefitinib & $71.2(\mathrm{NR})$ \\
\hline Sequist [30] & 98 & 34 & 31 & First-line & Gefitinib & $55(33-70)$ \\
\hline INOUE [31] & 99 & 25 & 16 & First-line & Gefitinib & 75 (54-96) \\
\hline RoseLL [32] & 2105 & 350 & 217 & Mixed & Erlotinib & 70.6 (NR) \\
\hline Rosell [33] & NR & 123 & 12 & First-line & Erlotinib & 90 (NR) \\
\hline TAMURA [34] & 118 & 32 & 28 & Mixed & Gefitinib & 75 (58-93) \\
\hline
\end{tabular}

RR: response rate; NR: not reported.

have significantly prolonged time to progression and increased survival rate compared with those with the exon 21 L858R point mutation $[40,41]$. In addition to evidence that EGFR mutational status may have predictive value, retrospective data from randomised, controlled trials, including INTACT and TRIBUTE study results, suggest that EGFR mutational status also has prognostic value, with patients harbouring EGFR mutations demonstrating prolonged survival compared with those who do not, regardless of treatment group assignment $[42,43]$.

Prospective studies have assessed the efficacy of first-line EGFR TKIs in patients harbouring EGFR mutations. One example is the iTARGET trial, in which patients with advanced NSCLC harbouring EGFR mutations (including, but not restricted to, the L858R and exon 19 deletion mutations) received first-line gefitinib [30]. Of 98 patients screened, 34 had EGFR mutations and 31 received gefitinib. RR, the primary end-point, was 55\%; median PFS was 9.2 months (95\% CI 6.211.8 months) [30]. This study used clinical characteristics to enrich the patient population for those likely to be EGFR mutation-positive, demonstrating that genotype-directed therapy with EGFR TKIs is feasible in a US population, where the overall frequency of EGFR mutations is relatively low, compared with Asian populations.

Another prospective study of advanced NSCLC was carried out by the Spanish Lung Cancer Group, in which patients with EGFR mutations were selected to receive first-line treatment with erlotinib. Lung tumours from 2,105 patients were screened; EGFR mutations were found in 350 (16.6\%) of these and 217 received erlotinib, among them, 113 patients received erlotinib as first-line treatment. In these patients, median PFS was 14.0 months (95\% CI 11.3-16.7 months) and median OS was 27 months. This study cohort demonstrated that largescale screening of patients for EGFR mutations and customised treatment with EGFR TKIs are feasible [32].
Taken together, the studies described above demonstrate that EGFR TKIs are highly effective in selected patients, with treatment producing improved response rates and PFS compared with chemotherapy. Results from these studies also support the concept that, in a particular patient subgroup, firstline treatment with EGFR TKIs may be the most effective option. A prospective, randomised study to differentiate between the prognostic and predictive value of EGFR mutations, and to determine the optimal treatment strategy for different subgroups of NSCLC patients was needed. More recently, the first such study was completed and published.

The results from the Iressa Pan-Asia Study (IPASS) of first-line gefitinib versus carboplatin/paclitaxel in 1,217 clinically selected patients with advanced NSCLC [29] have considerable implications for clinical practice. Eligible patients were neveror light ex-smokers with adenocarcinoma histology; the overall rate of EGFR mutations in the 437 evaluable patients with available tissue was 59.7\%. Gefitinib had a superior PFS compared to chemotherapy, exceeding the primary end-point of the trial, which was to show noninferiority. The molecular subgroup analysis demonstrated that patients with EGFR mutations had superior PFS in the gefitinib arm compared with those in the chemotherapy arm (HR 0.48, 95\% CI $0.36-$ $0.64 ; \mathrm{p}<0.001$; treatment by EGFR mutations status interaction test, $\mathrm{p}<0.0001$ ) [29]. A crucial observation from this study is taken from the patients whose tumours had wild-type EGFR. In those patients, all of whom had clinical characteristics typical of gefitinib responders, those receiving gefitinib had a marked decline in PFS compared with those who received chemotherapy (HR 2.85, 95\% CI 2.05-3.98; p<0.001) [29]. This argues strongly that mutational testing should become standard practice at diagnosis, at least for adenocarcinoma patients with a never- or low smoking history, as clinical predictors are insufficient to optimise treatment. Such patients should be treated with first-line EGFR TKI therapy if their tumours harbour activating EGFR mutations, given the 
demonstrated PFS benefit, and chemotherapy should be the preferred therapy for those patients with wild-type EGFR. OS analysis on the IPASS trial is not yet completed. However, other studies support its conclusions; for example, in a smaller phase III study comparing first-line gefitinib with carboplatin/ paclitaxel in patients known to have EGFR mutation-positive advanced NSCLC, PFS was significantly prolonged in the gefitinib group in an interim analysis (10.4 versus 5.5 months; HR 0.4; log rank $\mathrm{p}<0.001$ ) [44]. This was also confirmed by another, more recently published phase III trial comparing first-line gefitinib with cisplatin plus docetaxel in NSCLC patients harbouring EGFR mutations. The gefitinib group had significantly prolonged median PFS compared with the patients receiving cisplatin plus docetaxel $(9.2$ versus 6.3 months; HR 0.489; log rank $\mathrm{p}<0.0001$ ) [36].

It is important to note that IPASS was an Asian study, and that activating EGFR mutations occur at a lower frequency in Caucasian populations ( $\sim 40$ and $\sim 10 \%$, respectively). Some feel that this may play a role in determining the uptake of mutational testing before first-line therapy, although it could be argued that it is more important to perform the definitive test in a population with a lesser chance of mutation. In addition to its implications for therapy choice, IPASS also set a new standard for the collection and analysis of biomarker data within large-scale clinical studies; this has an important bearing on tissue collection and analysis in future studies. Further prospective clinical trials are needed to confirm these findings in a study population that is not entirely Asian, validate that the same trend is seen with other chemotherapeutics (e.g. pemetrexed), and to examine whether the sequence of chemotherapy and EGFR TKI therapy in patients with mutations influences survival and other outcomes. For example, in a recently published retrospective study including 152 NSCLC patients with exon 19 deletions or L858R, those receiving first-line gefitinib had a significantly higher $R R$ than chemotherapy-treated patients (76 versus $54 \%$; $\mathrm{p}=0.005$ ). However, OS and PFS did not differ significantly between chemotherapy-naïve and -pretreated groups $(p=0.207$ and $p=0.804$, respectively) [45]. It is also important to note that patients with EGFR mutations also have a higher $\mathrm{RR}$ to chemotherapy compared to patients with wild-type EGFR. This was demonstrated by a phase III, open-label study investigating the efficacy of gefitinib compared with carboplatin plus paclitaxel in patients with NSCLC. During that study, EGFR mutation-positive patients were shown to have a higher objective RR to carboplatin/paclitaxel chemotherapy than patients with wild-type EGFR (47.3 versus 23.5\%) [29]. Physicians need to consider this information alongside data from mutational testing and the overall state of health of the patient when deciding on first- and second-line therapy until more conclusive evidence is available; in the long term, data on patient selection may also have an impact on social security reimbursement in European countries. In addition to these considerations, the time to initiation of therapy with EGFR TKIs requires clarification in cases of aggressive disease in which it may not be appropriate to wait for the results of EGFR mutation testing. Furthermore, as it is likely that most patients will, at some point, receive treatment with an EGFR TKI, the risk of patients with EGFR mutations experiencing side-effects from first-line chemotherapy that preclude further treatment, or of new metastases occurring at progression, should always be considered when selecting a first-line treatment.

\section{RESISTANCE TO EGFR TKIS: NEED FOR A NEW GENERATION OF TARGETED THERAPY}

Although patients with EGFR mutations initially tend to have a good therapeutic response to erlotinib or gefitinib, prolonged administration of either drug invariably leads to secondary resistance, with patients experiencing relapse or tumour progression [25].

To date, two principal mechanisms have been identified that underlie secondary resistance (fig. 1). One is a resistance mutation in the EGFR gene, T790M [47, 48], which impairs the binding of the reversible TKIs erlotinib or gefitinib to the adenosine triphosphate binding pocket of the EGFR tyrosine kinase, rendering them ineffective [49]. T790M occurs in $\sim 50 \%$ of patients with acquired resistance to gefitinib/erlotinib $[47,50]$. Some studies have suggested that, rather than causing

a)

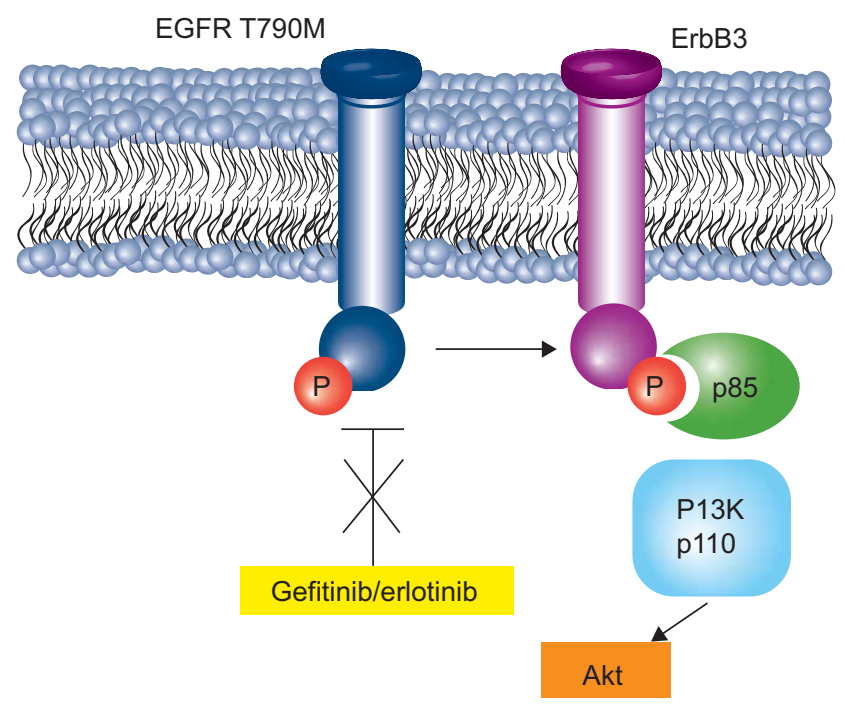

b)


FIGURE 1. a) The T790M mutation prevents erlotinib/gefitinib from effectively inhibiting phosphorylation of epidermal growth factor receptor (EGFR). b) MET amplification activates phosphoinositide 3-kinase (PI3K) signalling via ErbB3, independently of EGFR. Reproduced from [46] with permission from the publisher. 
the mutation to arise, treatment with TKIs simply selects for the resistant clones. Molecular characterisation of tumour tissue from 27 patients with metastatic NSCLC using an ultrasensitive, allele-specific assay revealed that low levels of T790M EGFR were present in 38\% of patients. The presence of the T790M mutation was associated with a significantly shorter PFS with EGFR TKI therapy compared with patients who did not have detectable levels of T790M at baseline, although it did not preclude response [51]. Although other mutations in exons 19-21 have been identified that also confer resistance to EGFR TKIs [52], T790M is the most common.
Irreversible TKIs that bind covalently with the catalytic pocket of EGFR are believed to provide a sustained blockade of EGFR signalling and may also retain activity against tumours that harbour resistance mutations, such as EGFR T790M. Several such agents are under clinical development for the treatment of various tumour types, including EKB-569 [53], CI-1033 [54], PF-00299804 [55] and BIBW 2992 [56] (table 2). In NSCLC, it is crucial to perform studies of these drugs in patients with EGFR mutations, both in those naïve to therapy with first-generation TKIs, such as gefitinib and erlotinib, and in those who have progressed through prior TKI therapy. Preliminary phase II

TABLE 2 Irreversible epidermal growth factor receptors (EGFR) inhibitors and MET inhibitors in clinical development in nonsmall cell lung cancer (NSCLC)

\begin{tabular}{|c|c|c|c|}
\hline Agent & Target & $\begin{array}{l}\text { Development } \\
\text { phase }\end{array}$ & Ongoing phase II/III studies \\
\hline \multicolumn{4}{|l|}{ Irreversible EGFR inhibitors } \\
\hline EKB-569 & EGFR & $\|$ & $\begin{array}{l}\text { Second-/subsequent-line EKB-569 in platinum- and docetaxel-refractory } \\
\text { patients with advanced NSCLC (study completed) }\end{array}$ \\
\hline $\mathrm{Cl}-1033$ & $\begin{array}{l}\text { EGFR, HER2 and } \\
\text { HER4 }\end{array}$ & $\|$ & $\begin{array}{c}\text { Second-/subsequent-line } \mathrm{Cl}-1033 \text { in patients with advanced/metastatic } \\
\text { NSCLC who have failed prior platinum-based combination } \\
\text { chemotherapy (study completed) }\end{array}$ \\
\hline \multirow[t]{4}{*}{ BIBW 2992} & EGFR and HER2 & $\|/ I\|$ & $\begin{array}{l}\text { Phase II: single-arm study of BIBW } 2992 \text { monotherapy in EGFR } \\
\text { FISH-positive patients }\end{array}$ \\
\hline & & & $\begin{array}{l}\text { Phase II: single-arm study of BIBW } 2992 \text { monotherapy in EGFR } \\
\text { mutation-positive patients }\end{array}$ \\
\hline & & & $\begin{array}{c}\text { Phase II single-arm study of BIBW } 2992 \text { monotherapy in patients } \\
\text { with EGFR mutations, HER2/neu mutations or EGFR FISH-positive } \\
\text { tumours with no EGFR mutations }\end{array}$ \\
\hline & & & $\begin{array}{l}\text { Phase IIB/III: BIBW } 2992 \text { in patients with NSCLC who have received } \\
1-2 \text { chemotherapy regimens (including one platinum-containing } \\
\text { regimen) and either gefitinib or erlotinib for a period of } \geqslant 12 \text { weeks } \\
\text { Phase III: First-line BIBW } 2992 \text { versus pemetrexed/cisplatin in patients } \\
\text { with lung adenocarcinoma bearing activating EGFR mutations }\end{array}$ \\
\hline XL647 & $\begin{array}{l}\text { EGFR, HER2 and } \\
\text { VEGFR2 }\end{array}$ & II & $\begin{array}{l}\text { Open-label study of XL647 monotherapy in previously untreated } \\
\text { NSCLC patients }\end{array}$ \\
\hline & & & $\begin{array}{l}\text { Open-label study of XL647 monotherapy in NSCLC patients who } \\
\text { have progressed after previously responding to gefitinib/erlotinib }\end{array}$ \\
\hline PF-00299804 & Pan-HER & $\|/ /\|$ & $\begin{array}{c}\text { Open-label study of PF-00299804 monotherapy in NSCLC patients } \\
\text { who have progressed after chemotherapy and erlotinib } \\
\text { Open-label study of PF-00299804 monotherapy in patients with } \\
\text { adenocarcinoma who are either non-smokers or former light smokers } \\
\text { PF-00299804 versus erlotinib in patients with advanced NSCLC who } \\
\text { have progressed after } 1 \text { or } 2 \text { prior chemotherapy regimens } \\
\text { PF-00299804 in patients with advanced NSCLC that has not } \\
\text { responded to standard therapy }\end{array}$ \\
\hline \multicolumn{4}{|l|}{ MET inhibitors } \\
\hline MET-Mab (antibody) & MET & $\|$ & $\begin{array}{l}\text { MET-Mab plus erlotinib versus erlotinib plus placebo in } \\
\text { second-/third-line NSCLC }\end{array}$ \\
\hline ARQ197 (small molecule; only non-ATP inhibitor) & MET & $|/| \mid$ & $\begin{array}{c}\text { Randomised study of ARQ197 plus erlotinib versus erlotinib plus } \\
\text { placebo in patients with advanced/metastatic NSCLC who have } \\
\text { progressed after one chemotherapy regimen }\end{array}$ \\
\hline XL184 (small molecule) & $\begin{array}{l}\text { MET, VEGFR2, } \\
\text { RET }\end{array}$ & $|/| \mid$ & $\begin{array}{l}\text { XL184 with or without erlotinib in patients with NSCLC who have } \\
\text { progressed after previously responding to erlotinib }\end{array}$ \\
\hline
\end{tabular}

Information on ongoing studies is current according to http://clinicaltrials.gov/ as of February 4, 2010. ATP: adenosine triphosphate; HER: human EGFR; VEGFR: vascular endothelial growth factor receptor; FISH: fluorescence in situ hybridisation. 
results from 67 patients with EGFR mutations receiving BIBW 2992 as a second-line treatment show that $66 \%$ achieved a partial response, with $51 \%$ of patients remaining progressionfree at 12 months [57]. If irreversible EGFR TKIs prove to be as effective as or superior to gefitinib and erlotinib, then defining their role in treating or preventing acquired resistance is of great interest.

The second major mechanism of acquired resistance is MET amplification, observed in $\sim 20 \%$ of patients with NSCLC who develop resistance to EGFR TKIs [58]. MET amplification activates phosphoinosite 3-kinase signalling via ErbB3, independently of EGFR. This allows signalling downstream of EGFR to continue, despite the presence of EGFR inhibitors [59]. MET amplification occurs independently of the T790M mutation, although both can occur simultaneously in the same patient [58,60]. A number of therapeutic strategies for the inhibition of MET or its ligand, hepatocyte growth factor, are currently under investigation in early-phase clinical trials (table 2) [61].

In general, combination treatment with EGFR TKIs and other agents targeting downstream or redundant pathways may have considerable clinical potential; combination treatment with the MTOR (mammalian target of rapamycin) inhibitor rapamycin and irreversible EGFR TKIs has shown activity in preclinical in vivo experiments in EGFR L858R/T790M mouse models [62].

With increasing knowledge about the molecular mechanisms of acquired resistance to EGFR TKIs, the clinical implications should be considered: will repeat mutational testing be required during the course of a patient's treatment? If so, are repeat biopsies needed or can sensitive methods be devised that allow mutations to be tested for in blood samples? Which samples are most informative, those from the primary tumour or those from metastases? In which order should treatments be administered to optimise response? Which agents are effective once the first-generation EGFR TKIs erlotinib and gefitinib are no longer effective?

\section{EGFR COPY NUMBER IN NSCLC: A MORE OPEN QUESTION THAN EGFR MUTATION}

In addition to EGFR mutations, other techniques for identifying patients who may benefit from treatment with EGFR TKIs have been studied. The most notable of these is EGFR fluorescence in situ hybridisation (FISH), which indicates whether there is an overall increase in EGFR gene copy number [63]. FISH results have been shown to correlate with increased sensitivity to gefitinib or erlotinib and increased survival [63-65].

Results from both the BR.21 and ISEL trials suggested that patients with increased gene copy number according to FISH had improved survival with EGFR TKI therapy, compared with placebo (BR.21 HR 0.43, 95\% CI 0.23-0.78 ( $\mathrm{p}=0.004)$; ISEL HR 0.61, 95\% CI 0.36-1.04 $(p=0.067))[66,67]$. However, biomarker analyses of the SATURN study indicate that increased EGFR copy number according to FISH does not have adequate predictive power to enable selection of patients for early second-line treatment with erlotinib over placebo [68]. Furthermore, in randomised trials comparing an EGFR TKI to chemotherapy, EGFR gene copy number by FISH has not always been associated with improved results on the TKI arm (table 3). Finally, in the Iressa NSCLC Trial Evaluating Response and Survival Versus Taxotere (INTEREST) study, no significant difference in OS between treatment arms was detected for any of the biomarkers assessed, including EGFR FISH, and EGFR mutation was more powerful than EGFR FISH analysis in predicting objective response and PFS in patients receiving gefitinib [70].

To date, one prospective clinical trial has selected patients for gefitinib therapy based on EGFR copy number according to FISH. Results from the phase II ONCOBELL study show that of 37 patients with sufficient tumour tissue for analysis, 25 (69.4\%) were EGFR FISH-positive. Patients who had EGFR FISH-positive status had a significantly higher RR than EGFR FISH-negative patients (68.0 versus $9.1 \%$; $\mathrm{p}<0.001$ ). EGFR FISHpositive patients also had a significantly longer time to progression than EGFR FISH-negative patients (7.6 versus 2.7 months, respectively; $\mathrm{p}=0.02$ ). These data suggest that EGFR FISH analysis may, indeed, predict response to gefitinib [71].

In conclusion, EGFR gene amplification together with EGFR mutation is a common finding and usually affects the mutant allele [72]. It is probable that the predictive value of EGFR FISH for EGFR TKI effectiveness is more likely a result of its association with EGFR mutations. In some cases, EGFR protein overexpression may result from EGFR amplification alone, but its impact on response to EGFR TKIs remains debatable.

\section{KRAS MUTATIONS IN NSCLC: DO THEY HAVE PREDICTIVE OR PROGNOSTIC VALUE?}

Somatic mutations in the oncogene KRAS have been associated with lack of primary response to EGFR TKIs in several studies. It is thought that mutations in codons 2, 12, 13 and 61 lead to constitutive activation of the RAS protein, which may allow tumour cells to grow independently of EGFR signalling and, thus, render them resistant to EGFR TKIs [73]. Mutations in KRAS occur in $\sim 25 \%$ of European patients with adenocarcinoma, although they are less common in Asian patients [74]. Increased frequency of KRAS mutations have been shown not to be significantly associated with age, sex or smoking history [73]. Therefore, seeing clinical characteristics only to identify those patients who have a very limited chance of responding to treatment with EGFR TKIs is not the best option, and molecular testing will be required.

Analysis of 206 tumours from the BR.21 study showed that $15 \%$ had mutations in codons 12 or 13 of KRAS. These patients did not appear to derive any benefit from erlotinib therapy, whereas patients with wild-type KRAS did appear to gain a survival benefit (HR 0.69; $\mathrm{p}=0.03$ ) [67]. In the TRIBUTE study, 55 out of $264(21 \%)$ patients had KRAS mutations, and those with KRAS mutations in the erlotinib arm exhibited significantly shorter OS than those in the chemotherapy-only arm (HR 2.1, 95\% CI 1.1-3.8; $\mathrm{p}=0.019$ ) [43]. Preliminary results from 246 patients with sequenced tumour specimens receiving erlotinib in the prospective Evaluation of the EGFR Mutation Status for the Administration of EGFR-TKIs in Non Small Cell Lung Carcinoma (ERMETIC) cohort show that KRAS mutations have no significant impact on PFS but negatively affect survival, whereas EGFR mutations strongly predict prolonged 
TABLE 3 Impact of epidermal growth factor receptor (EGFR) gene copy number and EGFR mutations in nonsmall cell lung cancer (NSCLC) treated by EGFR tyrosine kinase inhibitors

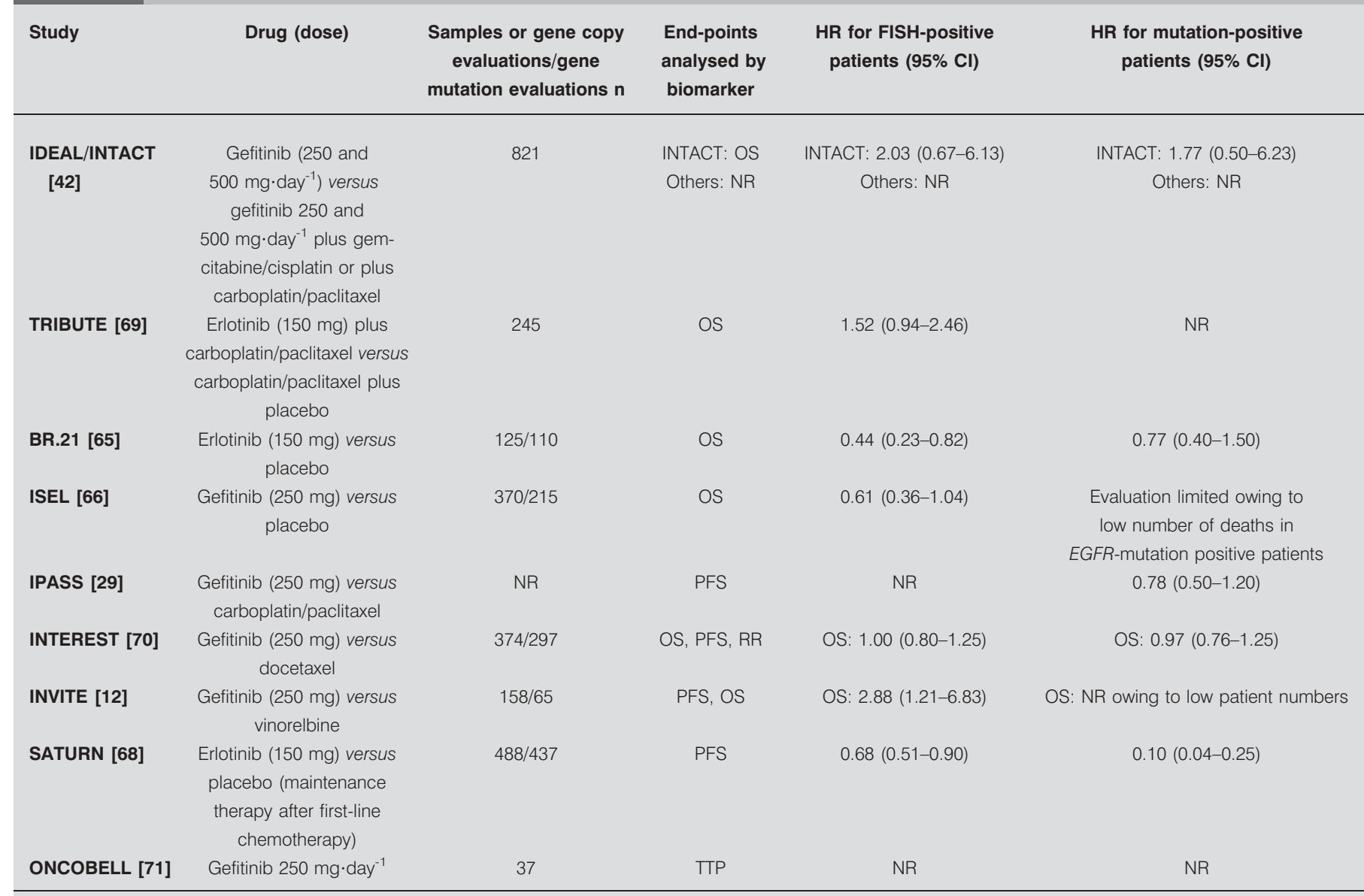

HR: hazard ratio; FISH: fluorescence in situ hybridisation; IDEAL: Incremental Decrease in Clinical Endpoints Through Aggressive Lipid Lowering; INTACT: Iressa NSCLC Trial Assessing Combination Treatment; TRIBUTE: Tarceva Responses in Conjunction with Taxol and Carboplatin; ISEL: Iressa Survival Evaluation in Lung Cancer; IPASS: Iressa PanAsia Study; INTEREST: Iressa NSCLC Trial Evaluating Response and Survival Versus Taxotere; INVITE: Iressa in NSCLC versus Vinorelbine Investigation in the Elderly; SATURN: Sequential Tarceva in Unresectable NSCLC; NR: not reported; OS: overall survival; PFS: progression-free survival; RR: response rate; TTP: time to progression.

PFS compared with wild-type EGFR, including all clinical and molecular markers [75].

As EGFR and KRAS mutations appear to be mutually exclusive [76-78], the possibility of defining these two biomarkers as predictors of response and resistance to EGFR TKIs, respectively, is generally accepted by many physicians, although simultaneously occurring mutations in EGFR and KRAS have been observed very rarely in tumours [43].

\section{ANTIBODIES TO EGFR IN NSCLC: WAITING FOR A PREDICTIVE BIOMARKER?}

Cetuximab, a humanised monoclonal antibody that prevents ligand binding to the extracellular domain of EGFR, has shown encouraging results in NSCLC in combination with standard chemotherapy, in both the first- and second-line settings [7983]. In the First-Line ErbituX in Lung Cancer (FLEX) study, a randomised, phase III study of cetuximab combined with cisplatin/vinorelbine (CV) versus $\mathrm{CV}$ alone in the first-line treatment of patients with EGFR immunohistochemistry (IHC)-positive advanced NSCLC, patients receiving cetuximab had statistically longer OS (primary end-point) than those receiving $\mathrm{CV}$ alone (11.3 versus 10.1 months; HR 0.871; $\mathrm{p}=0.044)$. There was no significant difference in PFS between treatment groups [82]. The role of EGFR copy number, KRAS mutation status and EGFR IHC values in the FLEX study have recently been reported [84]. A benefit from cetuximab treatment was seen regardless of either EGFR copy number, as assessed by FISH, or KRAS mutation status [84]. Currently, only a clinical characteristic is associated with increased PFS with cetuximab in FLEX: the early occurrence of skin rash. However, it is not thought that EGFR mutations play a crucial role in cetuximab activity as they do in EGFR TKI treatment, and cross-resistance with EGFR TKIs is unlikely to occur.

\section{MUTATION TESTING: THE NEED FOR STANDARDISATION}

Standardisation of sampling and test methodologies is essential to remove bias, allow comparison across trials and further our understanding of which patients may benefit from specific treatments. However, such efforts are hampered by a lack of 
consensus between centres on optimal methods and practical limitations, including tissue availability. Going forward, it is crucial to identify, standardise and validate methods of sampling and testing that are practicable across a wide number of hospital laboratories, and create evidence-based practice guidelines to facilitate comparison of test results between studies. The mutation status of EGFR is generally determined from samples taken by surgical resection, biopsy or fine-needle aspiration before treatment begins [27, 85-88]. Although minimally invasive fine-needle aspiration procedures have safety advantages for the patient, larger tissue samples, such as those provided by core biopsies, may allow more informative and reliable mutation testing. A further consideration is tumour heterogeneity: it remains unclear whether isolated biopsy samples are truly representative of the overall tumour and whether samples taken from a primary tumour may have a different profile than metastatic sites.

If a high fraction of neoplastic cells are present in a biopsy sample, direct sequencing to determine EGFR mutation status has been regarded as the gold standard [89]. Limitations in the feasibility of genomic DNA sequencing arise when tumour material available for PCR or RT-PCR is limited. In addition, direct sequencing techniques are relatively costly and timeconsuming.

The fixative used in pathologic preservation and the age of the samples can also affect the quality of sequencing test results. Formalin fixation can cause nucleic acid degradation, decreased amplicon length and PCR artefacts [90]. For example, in the molecular analysis of samples from the BR.21 trial of secondand third-line erlotinib, a large proportion of EGFR mutations were misidentified as uncommon novel transitions, an error caused by post mortem deamination of cytosine or adenine. These small aberrations can be artefactually amplified from low concentrations of tumour DNA and interpreted as significant when a small or old sample is analysed, whereas such deaminated sites are diluted and not detected when larger amounts of tumoural DNA are used $[89,91]$.

Biopsy samples with a large proportion of non-neoplastic cells are more suited to allele-specific assays, although these can only be used to assess the presence of a small number of predefined mutations. PCR-based assays are often the preferred choice here, due to their sensitivity, specificity, robustness and relative cost-effectiveness compared with direct sequencing. Because PCR-based assays look for predefined variants, they avoid the time-consuming steps of tissue microdissection and multiple rounds of DNA extraction, enabling their routine use in the clinical setting at acceptable cost. However, allele-specific PCR-based tests can only amplify known mutations in the selected EGFR regions. There are a plethora of different methods that have been published to identify EGFR mutations [35, 51, 92, 93].

Novel techniques are being developed to improve the feasibility of EGFR mutation testing from nontissue-based samples. Noninvasive testing of EGFR mutation status using serum samples and captured circulating tumour cells are under investigation [51, 94]. For example, the SMart Amplification Process (SMAP) is a single nucleotide polymorphism-based diagnostic assay that can be used to detect EGFR alterations from blood samples. HosHi et al. [95] adapted the SMAP technology to target three known hotspots for activating EGFR mutations, identifying the mutations with a high sensitivity within $30 \mathrm{~min}$ directly from blood samples. In addition, mutation-specific antibodies, which detect deletions in exon 19 and the L858R mutation in exon 21, have been developed and have shown high sensitivity and specificity when tested in paraffin-embedded tumour samples from NSCLC patients [96]. To simplify EGFR mutation testing and ease patient selection, one option is inclusion of a standardised, registered companion diagnostic test.

It remains a challenge to ensure that testing methods are used consistently and to encourage the realisation of biomarkerdirected treatment in NSCLC. Efforts are ongoing: for example, the French National Cancer Institute has implemented a 2-yr, multicentre, prospective study (ERMETIC). The primary objective of this study is to evaluate the ability of each of the participating 16 centres to perform biomarker assays, including EGFR exons 18-21 and KRAS exon 2 sequencing in paraffin-embedded tissues, as determined by the concordance of results between centres with those of an external molecular reference laboratory. After a pilot phase, during which all centres became familiar with the sequencing techniques involved, a prospective analysis has been undertaken of tumour samples from 522 EGFR TKI-naïve patients with stage IV NSCLC who received erlotinib at these centres. The objective of this part of the study was to assess the effectiveness of EGFR sequencing in identifying patients who are likely to benefit from treatment with erlotinib [75].

\section{CONCLUSIONS}

Having established the current state of evidence regarding genetic profiling and targeted therapy in NSCLC, what clinical implications can we draw? For now, EGFR TKIs should not be given as first-line treatment in the absence of an EGFR mutation test. However, we can now realistically envisage EGFR mutational testing becoming standard practice in NSCLC diagnostics, especially in patients with appropriate clinical predictors, such as never- but also former smoking patients. As this practice becomes increasingly common, important considerations include the timing of testing and standardisation of the methodology used; future efforts should be directed at developing a more practical test for EGFR mutations. For patients with EGFR mutations, the issue of secondary resistance must be addressed, and the sequence of chemotherapy in treatment paradigms that include EGFR TKIs must be more clearly defined. For patients with KRAS mutations, alternative targeted therapies may be more appropriate than EGFR TKIs and should be investigated further. For patients with neither EGFR nor KRAS mutations, representing the largest proportion of NSCLC patients, further studies to establish the best treatment options are still needed. However, it is likely that, because of what we have learned about EGFR mutations and EGFR TKIs over the past decade, development of future targeted therapies will include earlier investigation into the genotype of good responders and efforts will be focused on defining particular populations that benefit the most from treatment.

\section{SUPPORT STATEMENT}

Boehringer Ingelheim provided financial support for the assistance of Ogilvy Healthworld Medical Education. 


\section{STATEMENT OF INTEREST}

Statements of interest for all authors can be found at www.erj ersjournals.com/site/misc/statements.xhtml

\section{ACKNOWLEDGEMENTS}

The authors would like to acknowledge the editorial assistance of Ogilvy Healthworld Medical Education.

\section{REFERENCES}

1 Jobbagy Z, van Atta R, Murphy KM, et al. Evaluation of the Cepheid GeneXpert BCR-ABL assay. J Mol Diagn 2007; 9: 220-227.

2 Papadopoulos N, Kinzler KW, Vogelstein B. The role of companion diagnostics in the development and use of mutationtargeted cancer therapies. Nat Biotechnol 2006; 24: 985-995.

3 Slamon DJ, Leyland-Jones B, Shak S, et al. Use of chemotherapy plus a monoclonal antibody against HER2 for metastatic breast cancer that overexpresses HER2. N Engl J Med 2001; 344: 783-792.

4 Karapetis CS, Khambata-Ford S, Jonker DJ, et al. K-ras mutations and benefit from cetuximab in advanced colorectal cancer. $N$ Engl $J$ Med 2008; 359: 1757-1765.

5 Clark G. Prognostic factors versus predictive factors: examples from a clinical trial of erlotinib. Mol Oncol 2008; 1: 406-412.

6 Ciardiello F, Tortora G. EGFR antagonists in cancer treatment. N Engl J Med 2008; 358: 1160-1174.

7 Rusch V, Baselga J, Cordon-Cardo C, et al. Differential expression of the epidermal growth factor receptor and its ligands in primary non-small cell lung cancers and adjacent benign lung. Cancer Res 1993; 53: 2379-2385.

8 Fukuoka M, Yano S, Giaccone G, et al. Multi-institutional randomized phase II trial of gefitinib for previously treated patients with advanced non-small-cell lung cancer (The IDEAL 1 Trial). J Clin Oncol 2003; 21: 2237-2246.

9 Kris MG, Natale RB, Herbst RS, et al. Efficacy of gefitinib, an inhibitor of the epidermal growth factor receptor tyrosine kinase, in symptomatic patients with non-small cell lung cancer: a randomized trial. JAMA 2003; 290: 2149-2158.

10 Thatcher N, Chang A, Parikh P, et al. Gefitinib plus best supportive care in previously treated patients with refractory advanced non-small-cell lung cancer: results from a randomised, placebo-controlled, multicentre study (Iressa Survival Evaluation in Lung Cancer). Lancet 2005; 366: 1527-1537.

11 Kim ES, Hirsh V, Mok T, et al. Gefitinib versus docetaxel in previously treated non-small-cell lung cancer (INTEREST): a randomised phase III trial. Lancet 2008; 372: 1809-1818.

12 Crino L, Cappuzzo F, Zatloukal P, et al. Gefitinib versus vinorelbine in chemotherapy-naive elderly patients with advanced non-small-cell lung cancer (INVITE): a randomized, phase II study. J Clin Oncol 2008; 26: 4253-4260.

13 Giaccone G, Herbst RS, Manegold C, et al. Gefitinib in combination with gemcitabine and cisplatin in advanced non-small-cell lung cancer: a phase III trial: INTACT 1. J Clin Oncol 2004; 22: 777-784.

14 Herbst RS, Giaccone G, Schiller JH, et al. Gefitinib in combination with paclitaxel and carboplatin in advanced non-small-cell lung cancer: a phase III trial: INTACT 2. J Clin Oncol 2004; 22: 785-794.

15 Perez-Soler R, Chachoua A, Hammond LA, et al. Determinants of tumor response and survival with erlotinib in patients with nonsmall-cell lung cancer. J Clin Oncol 2004; 22: 3238-3247.

16 Shepherd FA, Rodrigues Pereira J, Ciuleanu T, et al. Erlotinib in previously treated non-small-cell lung cancer. N Engl J Med 2005; 353: 123-132.

17 Gatzemeier U, Pluzanska A, Szczesna A, et al. Phase III study of erlotinib in combination with cisplatin and gemcitabine in advanced non-small-cell lung cancer: the Tarceva Lung Cancer Investigation Trial. J Clin Oncol 2007; 25: 1545-1552.
18 Herbst RS, Prager D, Hermann R, et al. TRIBUTE: a phase III trial of erlotinib hydrochloride (OSI-774) combined with carboplatin and paclitaxel chemotherapy in advanced non-small-cell lung cancer. J Clin Oncol 2005; 23: 5892-5899.

19 Cappuzzo F, Ciuleanu T, Stelmakh L, et al. SATURN: A doubleblind, randomized, phase III study of maintenance erlotinib versus placebo following nonprogression with first-line platinum-based chemotherapy in patients with advanced NSCLC. I Clin Oncol 2009; 27: Suppl. 15, 8001.

20 Thatcher N. The ISEL and BR.21 trials - outcomes similar or different? Eur J Cancer 2006; 4: Suppl., 23.

21 Giaccone G, Rodriguez JA. EGFR inhibitors: what have we learned from the treatment of lung cancer? Nat Clin Pract Oncol 2005; 2: 554-561.

22 Cortes-Funes H, Gomez C, Rosell R, et al. Epidermal growth factor receptor activating mutations in Spanish gefitinib-treated nonsmall-cell lung cancer patients. Ann Oncol 2005; 16: 1081-1086.

23 Takano $\mathrm{T}$, Ohe $\mathrm{Y}$, Sakamoto $\mathrm{H}$, et al. Epidermal growth factor receptor gene mutations and increased copy numbers predict gefitinib sensitivity in patients with recurrent non-small-cell lung cancer. J Clin Oncol 2005; 23: 6829-6837.

24 Han SW, Kim TY, Hwang PG, et al. Predictive and prognostic impact of epidermal growth factor receptor mutation in nonsmall-cell lung cancer patients treated with gefitinib. J Clin Oncol 2005; 23: 2493-2501.

25 Sequist LV, Lynch TJ. EGFR tyrosine kinase inhibitors in lung cancer: an evolving story. Annu Rev Med 2008; 59: 429-442.

26 Asahina H, Yamazaki K, Kinoshita I, et al. A phase II trial of gefitinib as first-line therapy for advanced non-small cell lung cancer with epidermal growth factor receptor mutations. $\mathrm{Br} \mathrm{J}$ Cancer 2006; 95: 998-1004.

27 Yoshida K, Yatabe Y, Park JY, et al. Prospective validation for prediction of gefitinib sensitivity by epidermal growth factor receptor gene mutation in patients with non-small cell lung cancer. J Thorac Oncol 2007; 2: 22-28.

28 Sunaga N, Tomizawa Y, Yanagitani N, et al. Phase II prospective study of the efficacy of gefitinib for the treatment of stage III/IV non-small cell lung cancer with EGFR mutations, irrespective of previous chemotherapy. Lung Cancer 2007; 56: 383-389.

29 Mok TS, Wu YL, Thongprasert S, et al. Gefitinib or carboplatinpaclitaxel in pulmonary adenocarcinoma. $N$ Engl J Med 2009; 361: 947-957.

30 Sequist LV, Martins RG, Spigel D, et al. First-line gefitinib in patients with advanced non-small-cell lung cancer harboring somatic EGFR mutations. J Clin Oncol 2008; 26: 2442-9.

31 Inoue A, Suzuki T, Fukuhara T, et al. Prospective phase II study of gefitinib for chemotherapy-naive patients with advanced nonsmall-cell lung cancer with epidermal growth factor receptor gene mutations. J Clin Oncol 2006; 24: 3340-3346.

32 Rosell R, Moran T, Queralt C, et al. Screening for epidermal growth factor receptor mutations in lung cancer. N Engl J Med 2009; 361: 958-967.

33 Rosell R, Perez-Roca L, Sanchez JJ, et al. Customized treatment in non-small-cell lung cancer based on EGFR mutations and BRCA1 mRNA expression. PLOS ONE 2009; 4: e5133.

34 Tamura K, Okamoto I, Kashii T, et al. Multicentre prospective phase II trial of gefitinib for advanced non-small cell lung cancer with epidermal growth factor receptor mutations: results of the West Japan Thoracic Oncology Group trial (WJTOG0403). Br J Cancer 2008; 98: 907-914.

35 Sutani A, Nagai Y, Udagawa K, et al. Gefitinib for non-small-cell lung cancer patients with epidermal growth factor receptor gene mutations screened by peptide nucleic acid-locked nucleic acid PCR clamp. Br J Cancer 2006; 95: 1483-1489.

36 Mitsudomi T, Morita S, Yatabe Y, et al. Gefitinib versus cisplatin plus docetaxel in patients with non-small-cell lung cancer harbouring mutations of the epidermal growth factor receptor 
(WJTOG3405): an open label, randomised phase 3 trial. Lancet Oncol 2010; 11: 121-128.

37 Costa DB, Kobayashi S, Tenen DG, et al. Pooled analysis of the prospective trials of gefitinib monotherapy for EGFR-mutant nonsmall cell lung cancers. Lung Cancer 2007; 58: 95-103.

38 Sequist LV, Bell DW, Lynch TJ, et al. Molecular predictors of response to epidermal growth factor receptor antagonists in nonsmall-cell lung cancer. J Clin Oncol 2007; 25: 587-595.

39 Takano T, Fukui T, Ohe Y, et al. EGFR Mutations predict survival benefit from gefitinib in patients with advanced lung adenocarcinoma: a historical comparison of patients treated before and after gefitinib approval in japan. J Clin Oncol 2008; 26: 5589-5595.

40 Jackman DM, Yeap BY, Sequist LV, et al. Exon 19 deletion mutations of epidermal growth factor receptor are associated with prolonged survival in non-small cell lung cancer patients treated with gefitinib or erlotinib. Clin Cancer Res 2006; 12: 3908-3914.

41 Riely GJ, Pao W, Pham D, et al. Clinical course of patients with non-small cell lung cancer and epidermal growth factor receptor exon 19 and exon 21 mutations treated with gefitinib or erlotinib. Clin Cancer Res 2006; 12: 839-844.

42 Bell DW, Lynch TJ, Haserlat SM, et al. Epidermal growth factor receptor mutations and gene amplification in non-small-cell lung cancer: molecular analysis of the IDEAL/INTACT gefitinib trials. J Clin Oncol 2005; 23: 8081-8092.

43 Eberhard DA, Johnson BE, Amler LC, et al. Mutations in the epidermal growth factor receptor and in KRAS are predictive and prognostic indicators in patients with non-small-cell lung cancer treated with chemotherapy alone and in combination with erlotinib. J Clin Oncol 2005; 23: 5900-5909.

44 Inoue $\mathrm{A}$, Kobayashi $\mathrm{K}$, Maemondo $\mathrm{M}$, et al. A randomized phase III study comparing gefitinib with carboplatin (CBDCA) plus paclitaxel (TXL) for the first-line treatment of non-small cell lung cancer (NSCLC) with sensitive EGFR mutations: NEJ002 study. Eur J Cancer 2009; 7: Suppl., 9.

$45 \mathrm{Wu}$ JY, Yu CJ, Yang CH, et al. First- or second-line therapy with gefitinib produces equal survival in non-small cell lung cancer. Am J Respir Crit Care Med 2008; 178: 847-853.

46 Engleman JA, Janne PA. Mechanisms of acquired resistance to epidermal growth factor receptor tyrosine kinase inhibitors in non-small cell lung cancer. Clin Cancer Res 2008; 14: 2895-2899.

47 Balak MN, Gong Y, Riely GJ, et al. Novel D761Y and common secondary T790M mutations in epidermal growth factor receptormutant lung adenocarcinomas with acquired resistance to kinase inhibitors. Clin Cancer Res 2006; 12: 6494-6501.

48 Pao W, Miller VA. Epidermal growth factor receptor mutations, small-molecule kinase inhibitors, and non-small-cell lung cancer: current knowledge and future directions. J Clin Oncol 2005; 23: 2556-2568.

49 Yun CH, Mengwasser KE, Toms AV, et al. The T790M mutation in EGFR kinase causes drug resistance by increasing the affinity for ATP. Proc Natl Acad Sci USA 2008; 105: 2070-2075.

50 Kosaka T, Yatabe Y, Endoh H, et al. Analysis of epidermal growth factor receptor gene mutation in patients with non-small cell lung cancer and acquired resistance to gefitinib. Clin Cancer Res 2006; 12: 5764-5769.

51 Maheswaran S, Sequist LV, Nagrath S, et al. Detection of mutations in EGFR in circulating lung-cancer cells. N Engl J Med 2008; 359: 366-377.

52 Bean J, Riely GJ, Balak M, et al. Acquired resistance to epidermal growth factor receptor kinase inhibitors associated with a novel T854A mutation in a patient with EGFR-mutant lung adenocarcinoma. Clin Cancer Res 2008; 14: 7519-7525.

53 Yoshimura N, Kudoh S, Kimura T, et al. EKB-569, a new irreversible epidermal growth factor receptor tyrosine kinase inhibitor, with clinical activity in patients with non-small cell lung cancer with acquired resistance to gefitinib. Lung Cancer 2006; 51: 363-368.
54 Janne PA, von Pawel J, Cohen RB, et al. Multicenter, randomized, phase II trial of CI-1033, an irreversible pan-ERBB inhibitor, for previously treated advanced non small-cell lung cancer. J Clin Oncol 2007; 25: 3936-3944.

55 Gonzales AJ, Hook KE, Althaus IW, et al. Antitumor activity and pharmacokinetic properties of PF-00299804, a second-generation irreversible pan-erbB receptor tyrosine kinase inhibitor. Mol Cancer Ther 2008; 7: 1880-1889.

56 Eskens FA, Mom CH, Planting AS, et al. A phase I dose escalation study of BIBW 2992, an irreversible dual inhibitor of epidermal growth factor receptor 1 (EGFR) and 2 (HER2) tyrosine kinase in a 2-week on, 2-week off schedule in patients with advanced solid tumours. Br J Cancer 2008; 98: 80-85.

57 Yang CJ, Chao TJ, Shih J, et al. Use of BIBW 2992, a novel irreversible EGFR/HER2 TKI to induce regression in patients with adenocarcinoma of the lung and activating EGFR mutations: preliminary results of a single arm phase II clinical trial. J Clin Oncol 2008; 26: 8026.

58 Engelman JA, Zejnullahu K, Mitsudomi T, et al. MET amplification leads to gefitinib resistance in lung cancer by activating ERBB3 signaling. Science 2007; 316: 1039-1043.

59 Engelman JA, Janne PA. Mechanisms of acquired resistance to epidermal growth factor receptor tyrosine kinase inhibitors in non-small cell lung cancer. Clin Cancer Res 2008; 14: 2895-2899.

60 Bean J, Brennan C, Shih JY, et al. MET amplification occurs with or without T790M mutations in EGFR mutant lung tumors with acquired resistance to gefitinib or erlotinib. Proc Natl Acad Sci USA 2007; 104: 20932-20937.

61 Cipriani NA, Abidoye OO, Vokes E, et al. MET as a target for treatment of chest tumours. Lung Cancer 2009; 63: 169-179.

62 Li D, Ambrogio L, Shimamura T, et al. BIBW2992, an irreversible EGFR/HER2 inhibitor highly effective in preclinical lung cancer models. Oncogene 2008; 27: 4702-4711.

63 Cappuzzo F, Hirsch FR, Rossi E, et al. Epidermal growth factor receptor gene and protein and gefitinib sensitivity in non-smallcell lung cancer. J Natl Cancer Inst 2005; 97: 643-655.

64 Hirsch FR, Varella-Garcia M, McCoy J, et al. Increased epidermal growth factor receptor gene copy number detected by fluorescence in situ hybridization associates with increased sensitivity to gefitinib in patients with bronchioloalveolar carcinoma subtypes: a Southwest Oncology Group Study. J Clin Oncol 2005; 23: 6838-6845.

65 Tsao MS, Sakurada A, Cutz JC, et al. Erlotinib in lung cancer molecular and clinical predictors of outcome. N Engl J Med 2005; 353: 133-144.

66 Hirsch FR, Varella-Garcia M, Bunn PA Jr, et al. Molecular predictors of outcome with gefitinib in a phase III placebocontrolled study in advanced non-small-cell lung cancer. J Clin Oncol 2006; 24: 5034-5042.

67 Zhu CQ, da Cunha Santos G, Ding K, et al. Role of KRAS and EGFR as biomarkers of response to erlotinib in National Cancer Institute of Canada Clinical Trials Group Study BR.21. J Clin Oncol 2008; 26: 4268-4275.

68 Brugger W, Triller N, Blasinska-Morawiec M, et al. Biomarker analyses from the phase III placebo-controlled SATURN study of maintenance erlotinib following first-line chemotherapy for advanced NSCLC. J Clin Oncol 2009; 27: Suppl. 15, 8020.

69 Hirsch FR, Varella-Garcia M, Dziadziuszko R, et al. Fluorescence in situ hybridization subgroup analysis of TRIBUTE, a phase III trial of erlotinib plus carboplatin and paclitaxel in non-small cell lung cancer. Clin Cancer Res 2008; 14: 6317-6323.

70 Douillard J, Shepherd F, Hirsh V, et al. Molecular predictors of outcome with gefitinib and docetaxel in previously treated nonsmall-cell lung cancer: data from the randomized Phase III INTEREST trial. J Clin Oncol 2010; 28: 744-752.

71 Cappuzzo F, Ligorio C, Janne PA, et al. Prospective study of gefitinib in epidermal growth factor receptor fluorescence in situ hybridization-positive/phospho-Akt-positive or never smoker 
patients with advanced non-small-cell lung cancer: the ONCOBELL trial. J Clin Oncol 2007; 25: 2248-2255.

$72 \mathrm{Li} \mathrm{A}$, Chitale D, Riely G, et al. EGFR mutations in lung adenocarcinomas: clinical testing experience and relationship to the EGFR gene copy number and immunohistochemical expression. J Mol Diagn 2008; 10: 242-248.

73 Riely GJ, Kris MG, Rosenbaum D, et al. Frequency and distinctive spectrum of KRAS mutations in never smokers with lung adenocarcinoma. Clin Cancer Res 2008; 14: 5731-5734.

74 Pao W, Wang TY, Riely GJ, et al. KRAS mutations and primary resistance of lung adenocarcinomas to gefitinib or erlotinib. PLOS Med 2005; 2: e17.

75 Cadranel J, Lizard S, Mauguen A, et al. Impact of clinical and biological markers on progression-free survival (PFS) and overall survival (OS) in patients (pts) with advanced non-small-cell cancer (NSCLC) treated by erlotinib: results of the ERMETIC cohort. www.meet-ics.com/ wclc2009/pdf/PosterDiscussionSession-Sunday2August2009.pdf Date last accessed: September 30, 2010. Date last updated: August 2, 2009.

76 Kosaka T, Yatabe Y, Endoh H, et al. Mutations of the epidermal growth factor receptor gene in lung cancer: biological and clinical implications. Cancer Res 2004; 64: 8919-8923.

77 Shigematsu H, Lin L, Takahashi T, et al. Clinical and biological features associated with epidermal growth factor receptor gene mutations in lung cancers. J Natl Cancer Inst 2005; 97: 339-346.

78 Tam IY, Chung LP, Suen WS, et al. Distinct epidermal growth factor receptor and KRAS mutation patterns in non-small cell lung cancer patients with different tobacco exposure and clinicopathologic features. Clin Cancer Res 2006; 12: 1647-1653.

79 Belani CP, Schreeder MT, Steis RG, et al. Cetuximab in combination with carboplatin and docetaxel for patients with metastatic or advanced-stage nonsmall cell lung cancer: a multicenter phase 2 study. Cancer 2008; 113: 2512-2517.

80 Butts CA, Bodkin D, Middleman EL, et al. Randomized phase II study of gemcitabine plus cisplatin or carboplatin [corrected], with or without cetuximab, as first-line therapy for patients with advanced or metastatic non small-cell lung cancer. J Clin Oncol 2007; 25: 5777-5784.

81 Kim ES, Mauer AM, William WN Jr, et al. A phase 2 study of cetuximab in combination with docetaxel in chemotherapyrefractory/resistant patients with advanced nonsmall cell lung cancer. Cancer 2009; 115: 1713-1722.

82 Pirker R, Pereira JR, Szczesna A, et al. Cetuximab plus chemotherapy in patients with advanced non-small-cell lung cancer (FLEX): an open-label randomised phase III trial. Lancet 2009; 373: $1525-1531$.

83 Rosell R, Robinet G, Szczesna A, et al. Randomized phase II study of cetuximab plus cisplatin/vinorelbine compared with cisplatin/ vinorelbine alone as first-line therapy in EGFR-expressing advanced non-small-cell lung cancer. Ann Oncol 2008; 19: 362-369.

84 O'Byrne KA, Bondarenko I, Barrios C, et al. Molecular and clinical predictors of outcome for cetuximab in non-small cell lung cancer (NSCLC): Data from the FLEX study. J Clin Oncol 2009; 27: Suppl. $15,8007$.

85 Chou TY, Chiu CH, Li LH, et al. Mutation in the tyrosine kinase domain of epidermal growth factor receptor is a predictive and prognostic factor for gefitinib treatment in patients with non-small cell lung cancer. Clin Cancer Res 2005; 11: 3750-3757.

86 Nakajima T, Yasufuku K, Suzuki M, et al. Assessment of epidermal growth factor receptor mutation by endobronchial ultrasoundguided transbronchial needle aspiration. Chest 2007; 132: 597-602.

87 Pinter F, Papay J, Almasi A, et al. Epidermal growth factor receptor (EGFR) high gene copy number and activating mutations in lung adenocarcinomas are not consistently accompanied by positivity for EGFR protein by standard immunohistochemistry. J Mol Diagn 2008; 10: 160-168.

88 Savic S, Tapia C, Grilli B, et al. Comprehensive epidermal growth factor receptor gene analysis from cytological specimens of nonsmall-cell lung cancers. Br J Cancer 2008; 98: 154-160.

89 Eberhard DA, Giaccone G, Johnson BE. Biomarkers of response to epidermal growth factor receptor inhibitors in Non-Small-Cell Lung Cancer Working Group: standardization for use in the clinical trial setting. J Clin Oncol 2008; 26: 983-994.

90 Williams C, Ponten F, Moberg C, et al. A high frequency of sequence alterations is due to formalin fixation of archival specimens. Am J Pathol 1999; 155: 1467-1471.

91 Marchetti A, Felicioni L, Buttitta F. Assessing EGFR mutations. N Engl J Med 2006; 354: 526-528.

92 Dahse R, Berndt A, Kosmehl H. PCR-based testing for therapyrelated EGFR mutations in patients with non-small cell lung cancer. Anticancer Res 2008; 28: 2265-2270.

93 Tanaka T, Nagai Y, Miyazawa H, et al. Reliability of the peptide nucleic acid-locked nucleic acid polymerase chain reaction clampbased test for epidermal growth factor receptor mutations integrated into the clinical practice for non-small cell lung cancers. Cancer Sci 2007; 98: 246-252.

94 Kimura H, Kasahara K, Kawaishi M, et al. Detection of epidermal growth factor receptor mutations in serum as a predictor of the response to gefitinib in patients with non-small-cell lung cancer. Clin Cancer Res 2006; 12: 3915-3921.

95 Hoshi K, Takakura H, Mitani Y, et al. Rapid detection of epidermal growth factor receptor mutations in lung cancer by the SMartAmplification Process. Clin Cancer Res 2007; 13: 4974-4983.

$96 \mathrm{Yu}$ J, Kane S, Wu J, et al. Mutation-specific antibodies for the detection of EGFR mutations in non-small-cell lung cancer. Clin Cancer Res 2009; 15: 3023-3028. 